\title{
sciendo
}

CIVIL AND ENVIRONMENTAL ENGINEERING REPORTS

E-ISSN 2450-8594

CEER 2020; 30 (4): 0021-0032

DOI: $10.2478 /$ ceer-2020-0047

Original Research Article

\section{FLEXURAL STRENGTH OF STEEL-CONCRETE COMPOSITE BEAMS UNDER TWO-POINT LOADING}

\author{
Palanivelu SANGEETHA ${ }^{1}$, S. RAMANA GOPAL, A. JAI VIGNESHWAR, \\ K. VAISHNAVI, A. SRINIDHI
}

Department of Civil Engineering, Sri Sivasubramaniya Nadar College of Engineering, Tamil Nadu, Chennai

\begin{abstract}
This study investigates the flexural strength of simply-supported steel-concrete composite beams under two-point loading. A total of four specimens were tested to failure for varying parameters including type of connectors (stud and channel) and number of connectors (two and four). ANSYS software was used to establish the finite element models that can simulate the flexural behaviour of the composite beam. The test results show that a beam with channel connectors performs better than a beam with stud connectors. The composite beam with two connectors between the beam and slab causes additional deflection due to slippage in the connectors, when compared to the beam with four connectors. The results from the analytical model are in good agreement with the experimental results.
\end{abstract}

Keywords: steel-concrete composite beam, decking sheet, shear connector, load-strain, ANSYS

\section{INTRODUCTION}

1 Corresponding author: Associate Professor, Department of Civil Engineering, Sri Sivasubramaniya Nadar College of Engineering, Kalavakkam-603110, Tamil Nadu, Chennai sangeethap@ssn.edu.in 
Modern composite construction involves the use of steel-concrete composite beams, slabs, and columns in buildings. They are usually used in multi-storey buildings where greater spans between the columns are often required. Flexural capacity of the beam is a major parameter because of the larger cross section, which is influenced by the shear interaction between the steel beam and the concrete slab. Theoretically, interaction may be partial and full by providing proper shear connectors and reinforcing bars, which gives good flexural strength. A six-metre simply-supported steel-concrete composite beam under two-point loading was studied experimentally to measure the deflection and slip of the beam [1]. The study on the flexural strength of the composite beam under hogging moment was carried out by observing both experimental and analytical behaviour using ABAQUS, and also compared with the strength calculated using code provision [2]. The effect of partial shear connection on the deflection of the composite beams for both long and short spans was studied and compared using a finite element model [3]. The application of different types of bolts as shear connectors in the steel - concrete composite beam was studied and compared with a control steel beam. In this study, the bolt with a nut and hook as the shear connector showed better performance [4]. There are different types of shear connectors available of which the welded headed shear stud is the most popular mechanical shear connector used in steel-concrete composite flexural members because of its relatively fast installation process [5]. Xing et. al. [6] studied the behaviour of steel-concrete composite beams with varying parameters such as dimensions of the section, types of studs, and degree of shear interaction, and their study showed that a relatively larger degree of shear interaction can increase the elastic stage and delay the development of slippage, but may decrease the ductility of the composite beam. Vasdravellis and Uy [7] tested fourteen steel-concrete composite beams and one control steel beam. Their study showed that the main factors affecting the shear capacity of the composite beam are the slab thickness and degree of shear connection. Lin et al. [8,9] studied the mechanical behaviour of composite beams under negative bending moment, fatigue, and ultimate static loading. A study of a steel-concrete composite space truss and beam without decking sheet was carried out which demonstrated that by providing proper shear connectors, their was possible to achieve a composite action [10-13]. This paper focussed on the flexural behaviour of the composite beam with two types of shear connectors and showed that composite action between the concrete slab and steel beam are achieved by providing more shear connectors.

\section{EXPERIMENTAL STUDY}

Four steel-concrete composite specimens were denoted as $\mathrm{CB}-2 \mathrm{SC}, \mathrm{CB}-4 \mathrm{SC}$, $\mathrm{CB}-2 \mathrm{CC}, \& \mathrm{CB}-4 \mathrm{CC}$ in which $\mathrm{CB}$ represents composite beam, $2 \& 4$ represents 
the number of shear connectors, and SC \& $\mathrm{CC}$ represents stud connector and channel connector, respectively. An ISMB $150(150$ x $250 \mathrm{~mm})$ was used as steel beam, with a span of $1000 \mathrm{~mm}$ between the simple support. Stud connectors with dimensions as follows: head diameter $30 \mathrm{~mm}$, stud diameter $20 \mathrm{~mm}$, and height $40 \mathrm{~mm}$, made from mild steel, were welded to the top flange of the I beam along with trapezoidal ribbed decking sheet of thickness $3 \mathrm{~mm} .40$ x 40 x 40 channel connectors of $2 \mathrm{~mm}$ thickness made using mild steel were also used as shear connectors in the composite beam. Figure 1 shows the details of the specimen. All the specimens have been provided with timber formwork for placing the concrete. A normal concrete mix of 1:1.5:3 was used to cast the slab with a thickness of 80 $\mathrm{mm}$ including ribbed decking sheet. All the specimens were cast at the same time and then cured by applying curing agent Sethard S100 at room temperature. The compressive strength of the concrete was determined by testing three $150 \mathrm{~mm}$ cube samples after 28 days of curing under a compression-testing jack. The average compressive strength of the cube sample was 22.3 MPa. Figure 2 shows the specimens with welded shear connectors on the flange of the beam, along with the decking sheet.

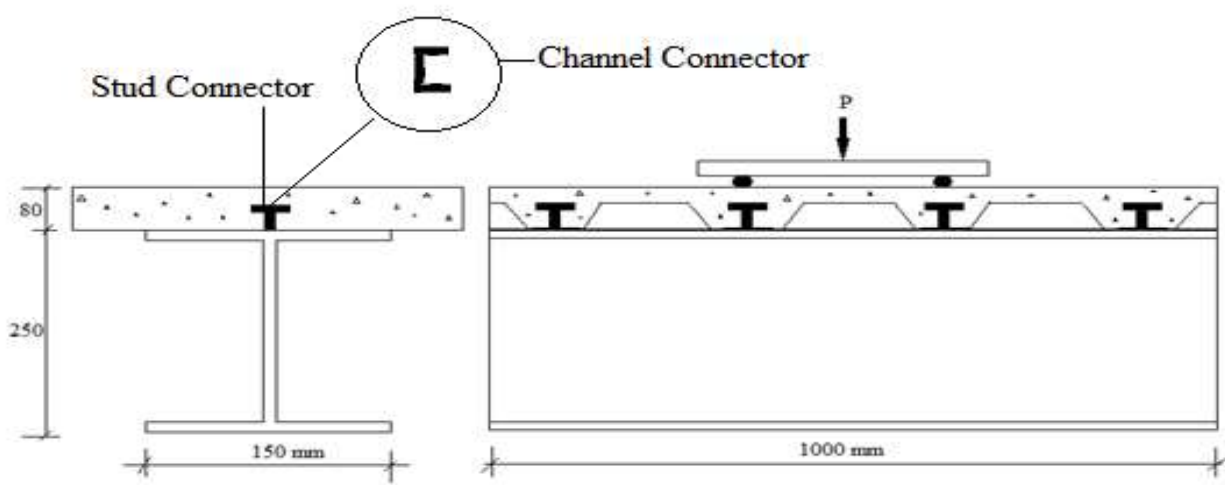

Fig.1. Details and specifications of the composite beam specimen
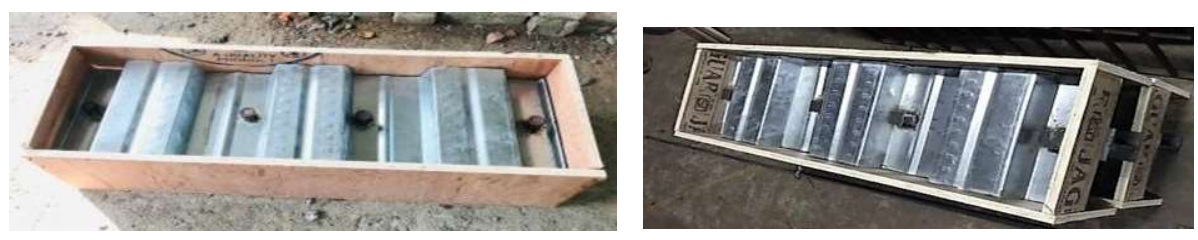

Fig. 2. Formwork for the specimen with welded decking sheet and shear connectors 
The concrete was placed in formwork by means of three layers, each layer being tamped uniformly along the length of the composite beam using a tamping rod. Figure 3 shows the beam specimens after placing of concrete. The curing of the specimen was carried out by applying the curing agent Sethard S100 directly onto the surface of the concrete portions. Figure 4 shows the composite beam specimen with strain gauges fixed in position. in total, three strain gauges and three dial gauges were used to measure the strain and deflection, respectively. The three strain gauges were used to measure the strain developed in the shear connectors, steel beam, and concrete slab. Similarly, the three dial gauges were fixed to measure the central deflection of the composite beam as well as slippage in both the steel and concrete. All the composite beams were subjected to two-point loading (i.e. four-point bending) using a Universal testing machine. Figure 5 shows the specimens under loading conditions.

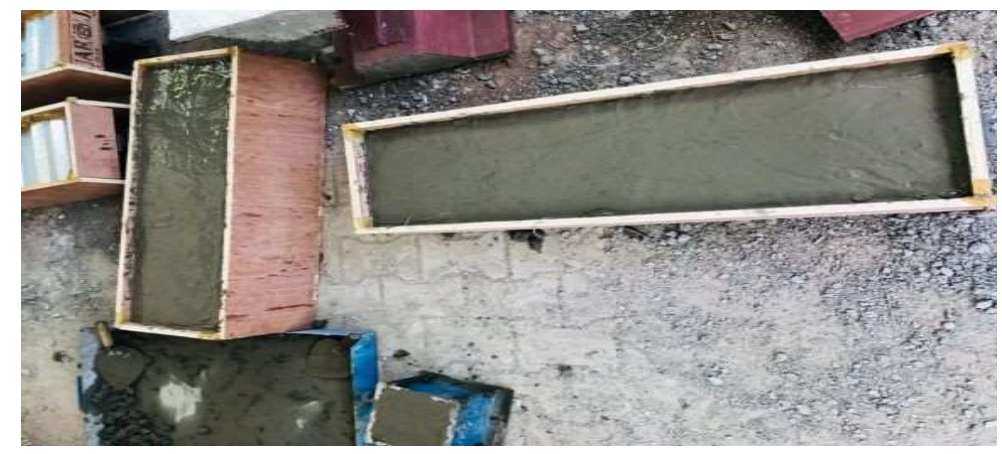

Fig. 3. Composite beam after placing of concrete

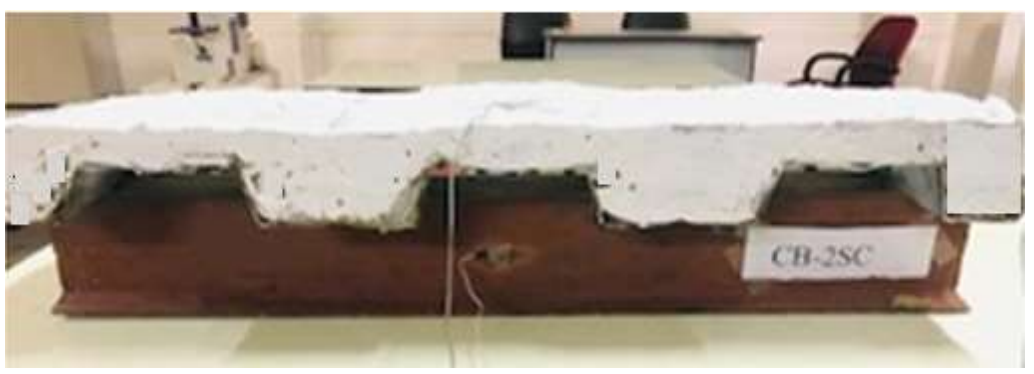

Fig. 4. Composite beam before testing 


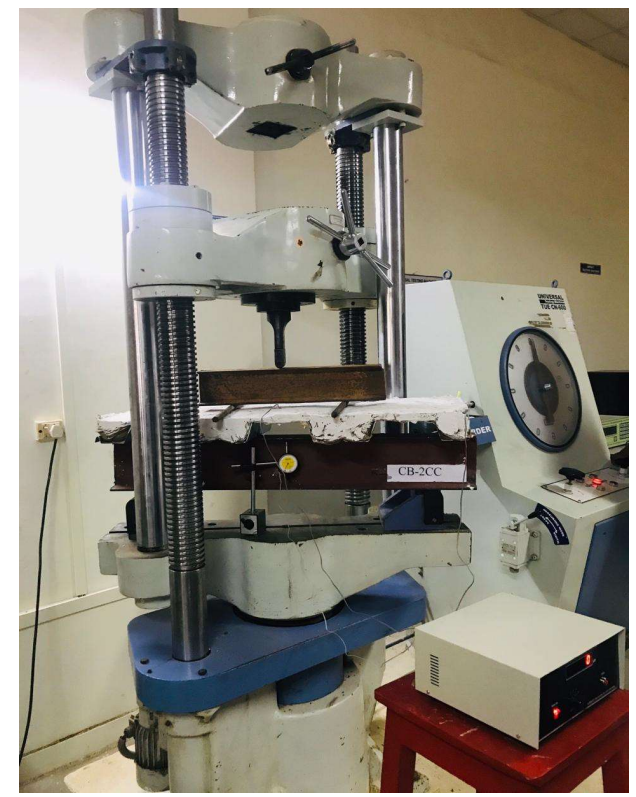

Fig. 5. Composite beam under loading

\section{ANALYTICAL STUDY}

All the steel-concrete composite beams were also modelled and analysed using the finite element software ANSYS in order to compare the results obtained by experiment with analytical study. From the element library of ANSYS, SOLID 186 (3D solid element for material non-linearity) was used to model the steel beam, decking sheet, and shear connectors, while SOLID 65 (able to capture cracking, crushing, and plastic deformation of concrete) was used to model the concrete. The material inputs are $2 \times 105 \mathrm{~N} / \mathrm{mm} 2$ and $20000 \mathrm{~N} / \mathrm{mm} 2$ for steel and concrete, respectively. Figures 6 and 7 show the mesh model of the steel beam with decking sheet and shear connector and the mesh model of the steel-concrete composite beam, respectively.

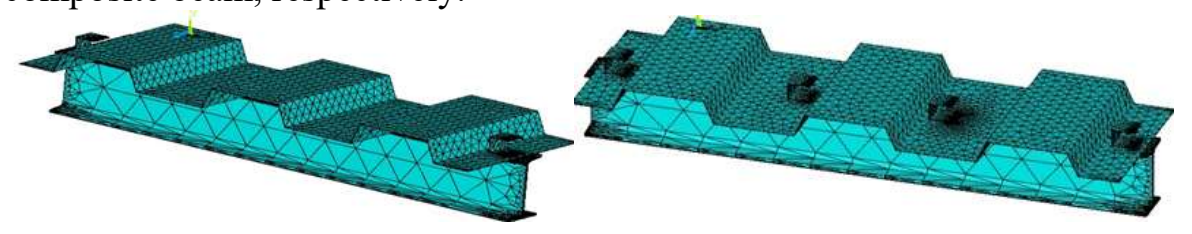




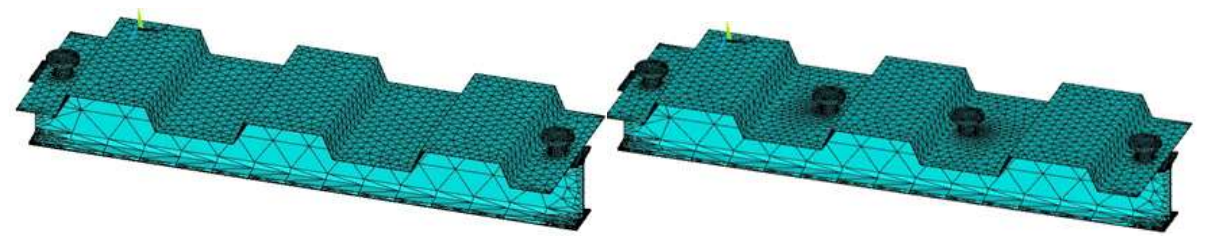

Fig.6. Mesh model of the steel beam, decking sheet, and shear connector

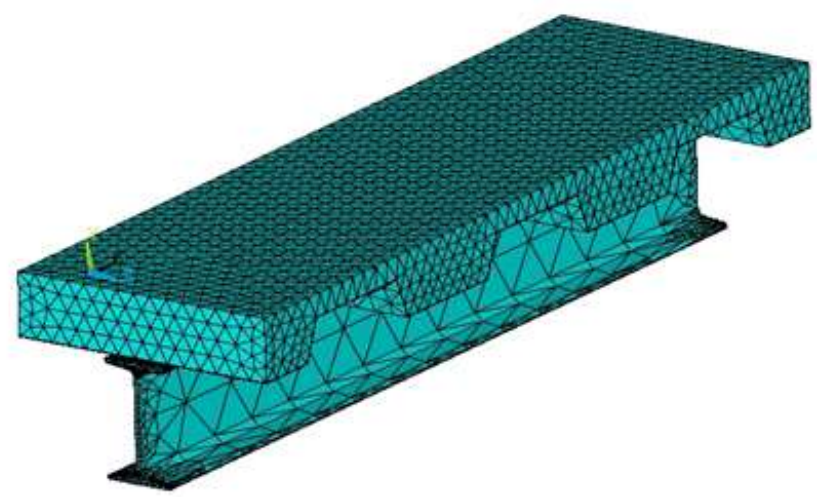

Fig.7. Mesh model of the steel-concrete composite beam

\section{RESULTS AND DISCUSSION}

\subsection{Load-deflection behaviour}

Figure 8 shows the plot made between the load and central deflection of the steelconcrete composite beam. From the graph, it can be seen that the performance of the channel connectors is good and able to resist the flexural load under two-point loading. The maximum load carrying capacity of the composite beam with four channel connectors is $120 \mathrm{kN}$. The trend of the graph shows that $\mathrm{CB}-4 \mathrm{CC}$ is able to resists more load, makes the beam more ductile, and offers good composite action. The increase in the flexural load carrying capacity of the beam is $65 \%$ for change of shear connector from stud to channel. The increase in the number of connectors from two to four increases the flexural strength by $45 \%$. Figure 9 gives the clear crack pattern on the surface of the composite slab. From the pattern, it is clear that more cracks appear under the loading point and from the location of the shear connectors. This may be due to stress concentration under the loads as well as the failure of the shear connectors. 

POINT LOADING

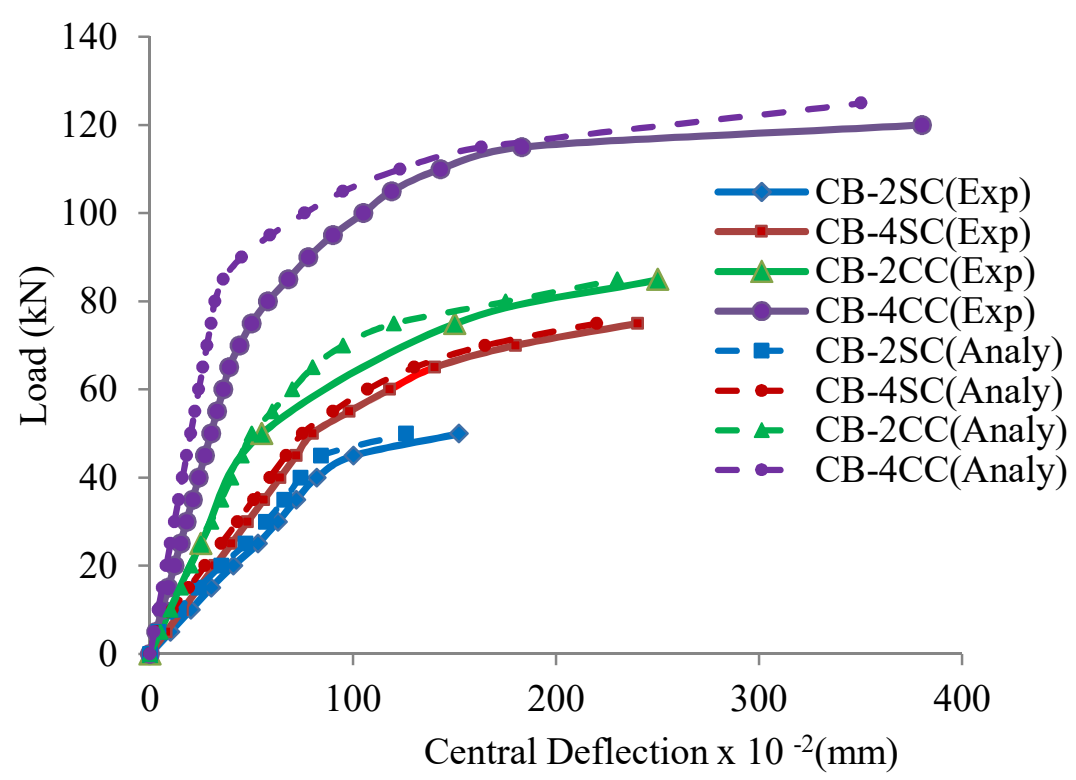

Fig. 8. Load-Central deflection of the composite beam
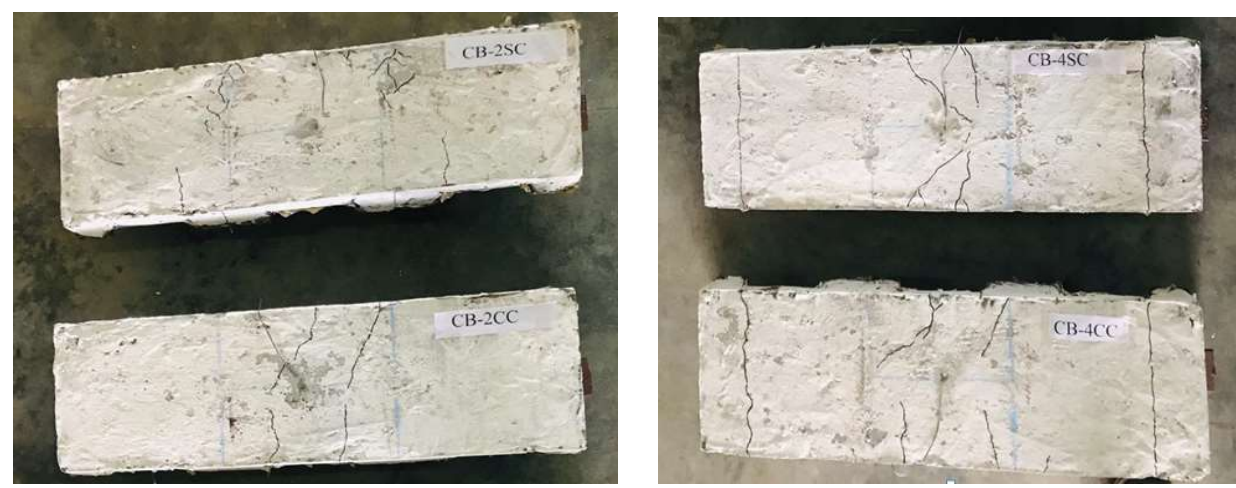

Fig. 9. Crack patterns on the composite beam

The stress distribution plots obtained from the ANSYS software are shown in Figures 10 and 11. The yellow colour indicates greater stress at the support point of the composite beam and the dark blue indicates locations of lower stress distribution. The formation of cracks in the composite beam were represented by blue patches on the top surface of the beam. The composite beams $\mathrm{CB}-4 \mathrm{SC}$ and $\mathrm{CB}-4 \mathrm{CC}$ show a clear crack pattern and ability to resist more deflection at the centre. 

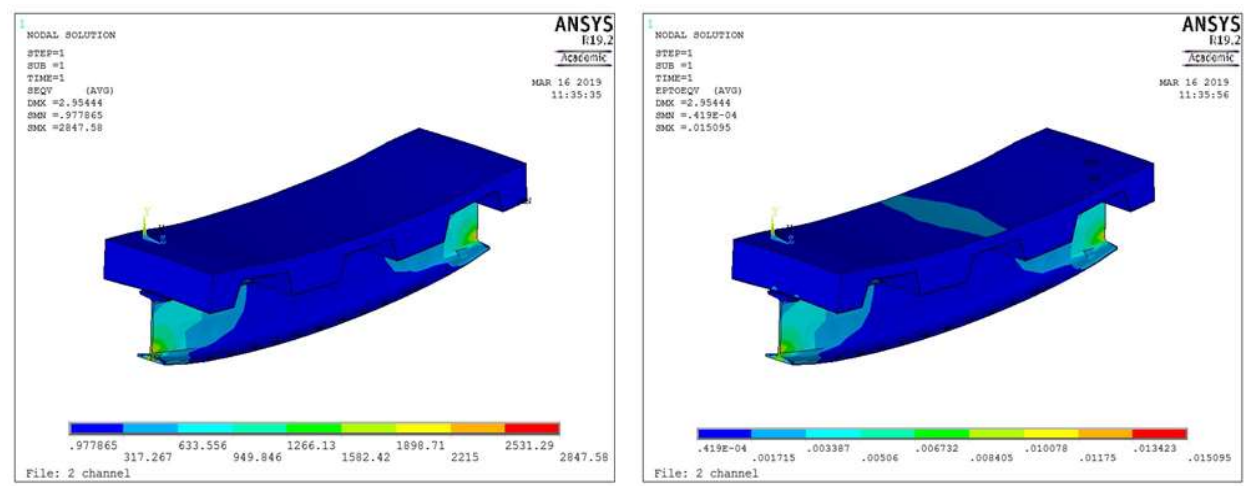

Fig. 10. Stress distribution plot of composite beam CB - 2SC and CB - 4SC
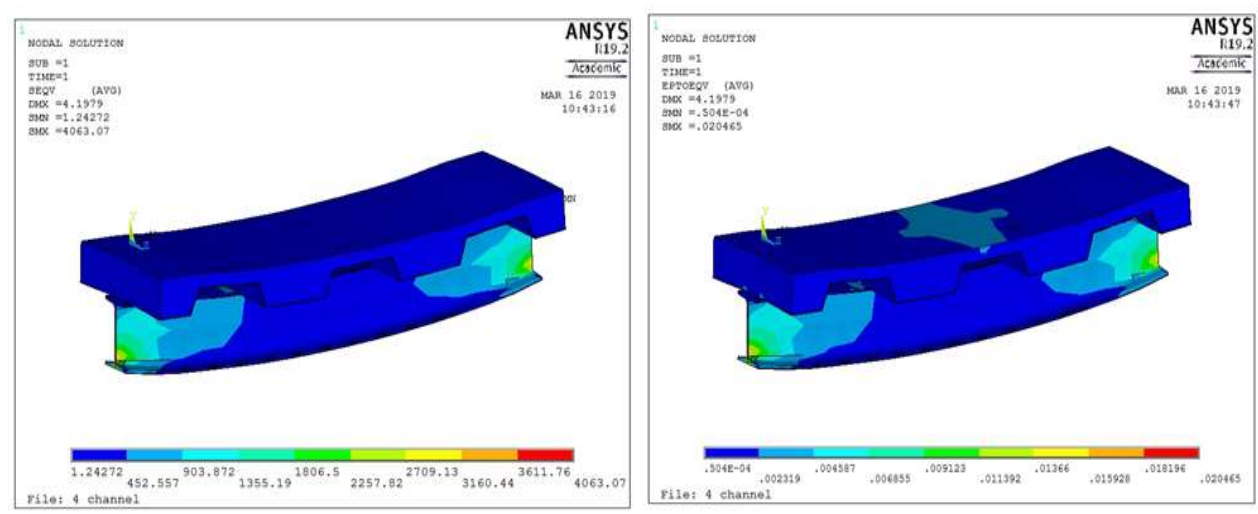

Fig. 11. Stress distribution plot of composite beam $\mathrm{CB}-2 \mathrm{CC}$ and $\mathrm{CB}-4 \mathrm{CC}$

\subsection{Load-strain behaviour}

Each composite beam was tested with three strain gauges of $20 \mathrm{~mm}$ gauge length, in order to record the strain from the shear connectors, concrete slab, and steel beam. The strains were recorded from the different locations separately using a five-channel strain indicator. Figure 12 shows the plot between the load and micro strain recorded from the shear connectors. The graph implies that the composite beam with channel connectors wase able to resist more load, with the maximum strain of 0.001 and 0.005 for 2 and 4 connectors, respectively. 


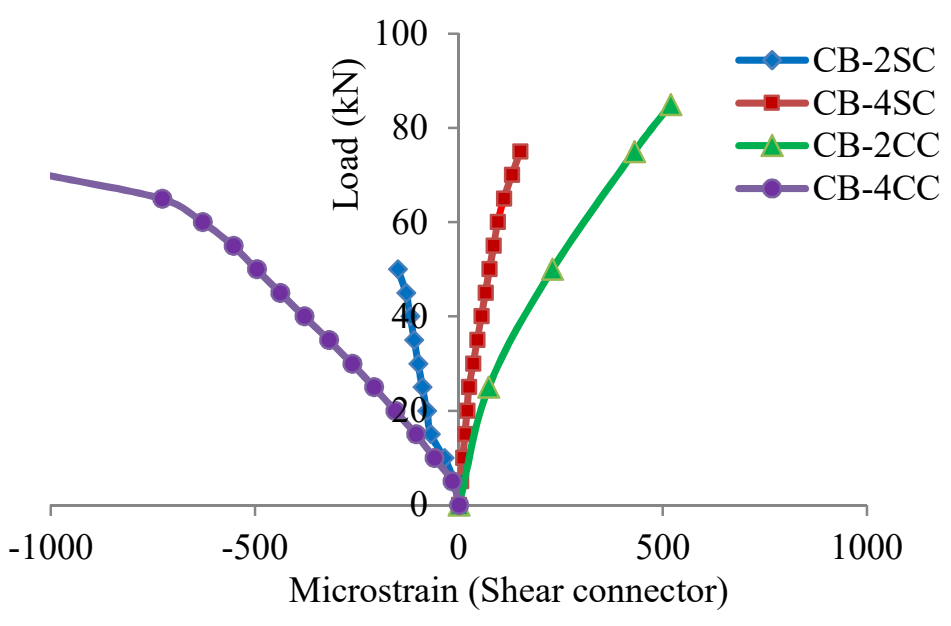

Fig. 12. Load-strain behaviour of the shear connector in the composite beam

Figure 13 shows the plot between the load and strain from the concrete slab. The strain observed from the concrete is as little as 0.0003 for $\mathrm{CB}-4 \mathrm{CC}$. The plot of $\mathrm{CB}-4 \mathrm{SC}$ shows the reversal of strain. This may be due to the failure of the shear connectors, which in turn triggers the failure of the composite beam.

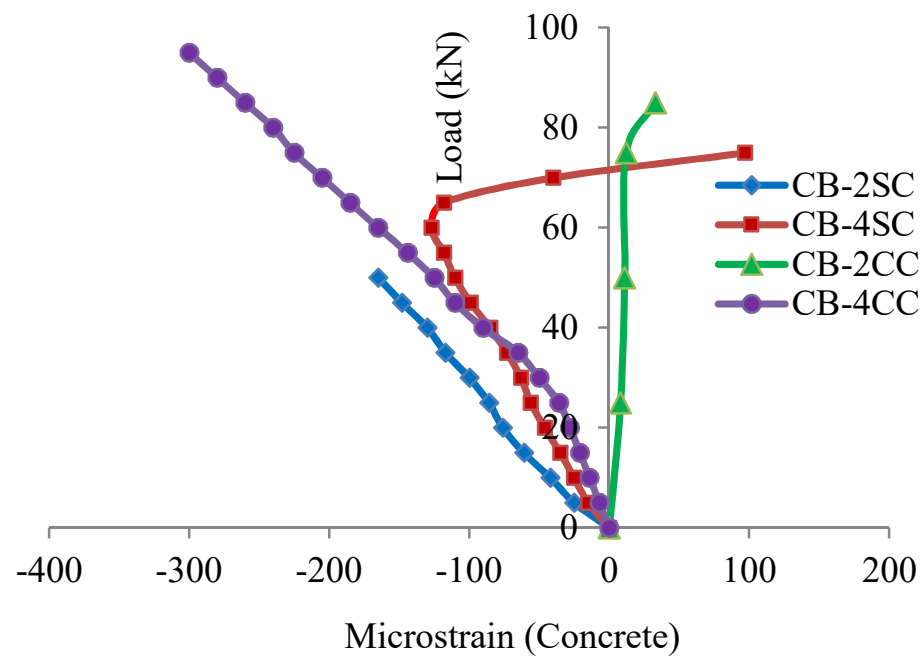

Fig. 13. Load-strain behaviour of the concrete slab in the composite beam 
The behaviour of the steel beams is shown in Figure 14. From this, it can be seen that the composite beam with channel connectors is stiffer than the beam with stud connectors. Table 1 gives the comparison between the experimental and analytical maximum central deflection of the steel-concrete composite beam under flexural loading. It was found that the ratio between the experimental and analytical deflection ranges from 1.08 to 1.16 .

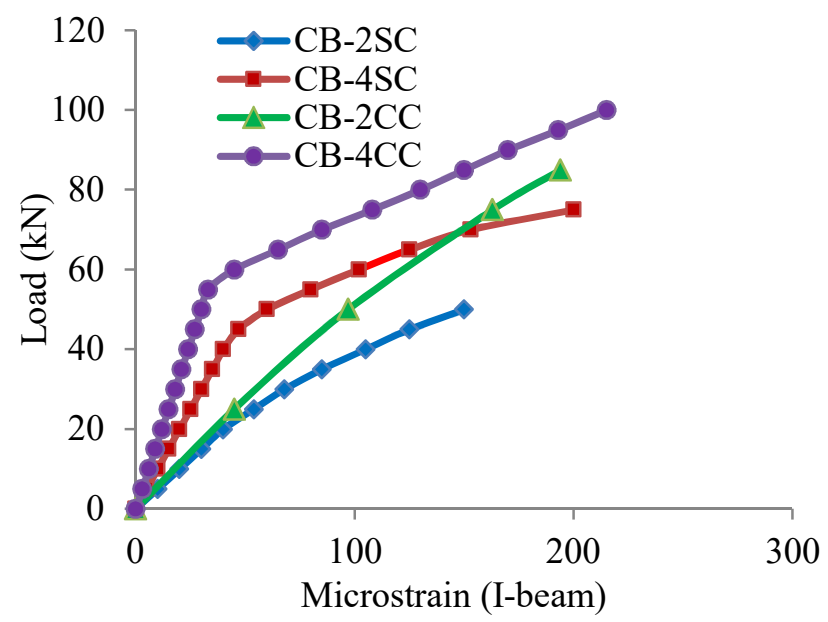

Fig. 14. Load-strain behaviour of the steel beam in the composite beam

Table 1. Comparison between experimental and analytical results

\begin{tabular}{|c|c|c|c|c|c|}
\hline $\begin{array}{c}\text { Sl. } \\
\text { No }\end{array}$ & Specimen & $\begin{array}{c}\text { Maximum } \\
\text { load } \\
(\mathbf{k N})\end{array}$ & $\begin{array}{c}\text { Maximum } \\
\text { central } \\
\text { deflection } \\
\boldsymbol{\Delta}_{\text {exp }} \\
(\mathbf{m m})\end{array}$ & $\begin{array}{c}\text { Maximum } \\
\text { central } \\
\text { deflection } \\
\boldsymbol{\Delta}_{\text {Ana }} \\
(\mathbf{m m})\end{array}$ & $\begin{array}{c}\boldsymbol{\Delta}_{\text {exp }} / \\
\boldsymbol{\Delta}_{\text {Ana }}\end{array}$ \\
\hline 1 & CB-2SC & 50 & 1.76 & 1.52 & 1.16 \\
\hline 2 & CB-4SC & 75 & 2.61 & 2.40 & 1.08 \\
\hline 3 & CB-2CC & 85 & 2.91 & 2.50 & 1.16 \\
\hline 4 & CB-4CC & 120 & 4.20 & 3.80 & 1.11 \\
\hline
\end{tabular}

\section{CONCLUSIONS}

The following conclusions were arrived at from the flexural study on the steelconcrete composite beam under two-point loading: 
1. It was found that the composite beam with channel connectors performs better than the beam with stud connectors under two-point loading conditions in terms of increasing load carrying capacity, reduced slippage, and being more resistant to deflection.

2. The increase in the flexural load carrying capacity of the composite beam with channel connectors is two-thirds greater than that of the composite beam with stud connectors.

3. The percentage increase in the flexural strength of the steel-concrete composite beam is $45 \%$ for an increase in the number of connectors from 2 to 4 .

4. The maximum strain of 0.001 was recorded for the composite beam $\mathrm{CB}$ $-4 \mathrm{CC}$, which is much lower and provides ductility.

5. The analytical model is stiffer than the experimental model due to the rigid connectors between the steel and concrete. The ratio between the experimental and analytical results of 1.08 to 1.16 shows good agreement and gives confidence for the use of the ANSYS model for finding the maximum deflection in further studies.

\section{CONFLICT OF INTEREST STATEMENT}

The author declares no conflict of interest in the publication of this article.

\section{REFERENCES}

1. Thondel, S and Studnicka, J 2013. Behaviour of steel - concrete composite beam with high ribbed deck, Procedia Engineering 40, 457-462.

2. Mark Lawson, R, Dennis Lam, Eleftherios, S, Aggelopoulos and Sebastain Nellinger, 2017. Serviceability performance of steel - concrete composite beams", Proceedings of Institute of Civil Engineering Structures and Building 170, 98 - 114.

3. Jing Liu, Fa-Xing Ding, Xue-Mei Liu, Zhi-Wu Yu, Zhe Tan and Jun Wen Huang 2019. Flexural capacity of steel - concrete composite beams under hogging Moment, Advances in Civil Engineering 2019, 1 - 14.

4. Minh-Tung Tran, Vuong Nguyen Van Do and Tuan-Anh Nguyen 2018. Behaviour of steel-concrete composite beams using bolts as shear connectors, IOP Conference Series: Earth and Environmental Sciences 143,1 - 8. 
5. Wang, B, Huang, Q, Liu, X and Li, W 2008. Experimental investigation of steel-concrete composite beams with different degrees of shear connection under monotonic and fatigue loads. Advances in Structural Engineering 21, 227-240.

6. Xing, Y, Han, Q, Xu, J, Guo, Q and Wang, Y 2016. Experimental and numerical study on static behaviour of elastic concrete-steel composite beams. Journal of Constructional Steel Research 123, 79-92, 2016.

7. B. V. Ga. U 2014. Shear strength and moment shear interaction in steelconcrete composite beams. Journal of Structural Engineering 140, 191-209.

8. Lin, W, Yoda, T, Taniguchi, N, Kasano, H and He, J 2014. Mechanical performance of steel-concrete composite beams subjected to a hogging moment. Journal of Structural Engineering 140, 1-9.

9. Lin, W, Yoda, T and Taniguchi, N 2014. Application of SFRC in steelconcrete composite beams subjected to hogging moment. Journal of Constructional Steel Research 101,175-183.

10. Sangeetha, P and Senthil, R 2018. A study on ultimate behaviour of composite space trusses. KSCE Journal of Civil Engineering 21,950-954.

11. Sangeetha, P and Ashwin Muthuraman, R 2018. Performance of steel concrete sandwich beam with varying shear connectors. Indian Journal of Science and Technology 11, 1-7.

12. Sangeetha, P and Senthil, R 2018. Experimental Study on the Service Load Behaviour of the Composite Space Truss. Journal of Structural Engineering (SERC) 44, 632-636.

13. Sangeetha, P 2018. Flexural behaviour of a cold - formed steel - concrete composite beam with channel type shear connectors - An Experimental and Analytical study. Civil and Environmental Engineering Report 30, 228-240. 